\title{
MECHANISTIC ANALYSIS OF FAT LOSS AND REGAIN BY USING AN IN VITRO HUMAN ADIPOCYTE MODEL SYSTEM
}

\author{
Qi Qiao, Edwin C. M. Mariman, and Johan Renes
}

Department of Human Biology, NUTRIM, Maastricht University, The Netherlands

\section{Introduction}

The prevalence of overweight and obesity has risen in recent years, causing a global public health problem due to an increased risk for the development of cardiometabolic diseases (atherosclerosis, hypertension, type 2 diabetes mellitus, metabolic syndrome) and cancers (1). The white adipose tissue (WAT) is a major player in the link between overweight and health complications. One factor is the fat storage capacity of the WAT because lipid overload leads to ectopic lipid accumulation in other peripheral tissues like skeletal muscle (2) and liver (3). This often leads to insulin resistance (4). Another role of the WAT in the link between overweight and health complications lies in the secretion by the adipocytes of over 600 peptide hormones, referred to as adipokines (5), which regulate whole body metabolism $(5,6)$. When people become obese, the profile of secreted peptide hormones changes as for instance is obvious from a decrease in the plasma level of adiponectin, a multifunctional adipokine that increases glucose uptake by skeletal muscle.

\section{Obesity and weight loss}

Weight loss is an indicated remedy for overweight/obesity that can reduce these risks. Already at $5 \%$ weight loss a decreased adipocyte size and an improved circulating adipokine profile was observed with obese woman after a 3-week low calorie diet (7). In addition we showed that the adipokine profile of in vitro cultured human Simpson-Golabi-Behmel syndrome (SGBS) adipocytes improved considerably after $96 \mathrm{hrs}$ of glucose starvation (8). Despite these positive results, up to $80 \%$ of the people who lose weight on a low energy diet, regain weight and often return to their original weight or even beyond within one or two years (9). Previously we proposed the idea that adipocytes can reduce fat contents only to a certain degree because the remodeling of the extracellular matrix (ECM) cannot keep up with the rate of fat loss. As a consequence stress will build up between the ECM and the cell wall due to traction forces that will slow down a further release of fat (10). This idea resulted in new a study in which obese subjects were subjected to an 8-week diet 
programme with a 10 -month follow-up. Compared to weight maintainers, weight regainers showed increased expression of $\beta$-actin, calnexin, heat shock proteins (HSP) 27, HSP60 and HSP70 in their subcutaneous adipose tissue. This shows that cellular stress accumulated during weight loss appears a driving factor for weight regain. In a parallel experiment with human SGBS adipocytes increased levels of $\beta$-actin and HSP60 were observed after 96 hrs glucose starvation (8), indicating the suitability of this in vitro model to study starvation and weight regain in a more mechanistic manner.

\section{SGBS cells as model for mechanistic analysis of fat loss and regain}

The SGBS cells proved to be a versatile model to study adipocyte differentiation and starvation in more detail $(8,11)$ (Fig. 1). As an extension to this, we will use starved SGBS adipocytes and study the refeeding process in relation to stress-induced weightregain. In the refeeding process, we will challenge the starved SGBS adipocytes with different glucose concentrations ranging from $0.55 \mathrm{mM}$ to $17.5 \mathrm{mM}$ or with different concentrations of fatty acids ranging from $0.5 \mathrm{mM}$ to $5.0 \mathrm{mM}$ (Fig. 2). Our objective is to find out the conditions that can prevent cell stress and prolong the reduced weight state in adipocytes. For this we will use Western blotting to monitor the expression of selected stress proteins. In addition we will use quantitative liquid chromatography tandem mass spectrometry (LC-MSMS) to discover changes in protein patterns that give further insight in the molecular mechanisms involved in starvation and refeeding.

\section{Conclusion}

By using the SGBS model and our proteomics technology we can find out how a cycle of fat loss and regain alters the human adipocyte metabolism. This may open the way to find conditions that can diminish cellular stress during fat loss and regain in man.

Conflict of interest statement: The authors declare that the research was conducted in the absence of any commercial or financial relationships that could be construed as a potential conflict of interest.

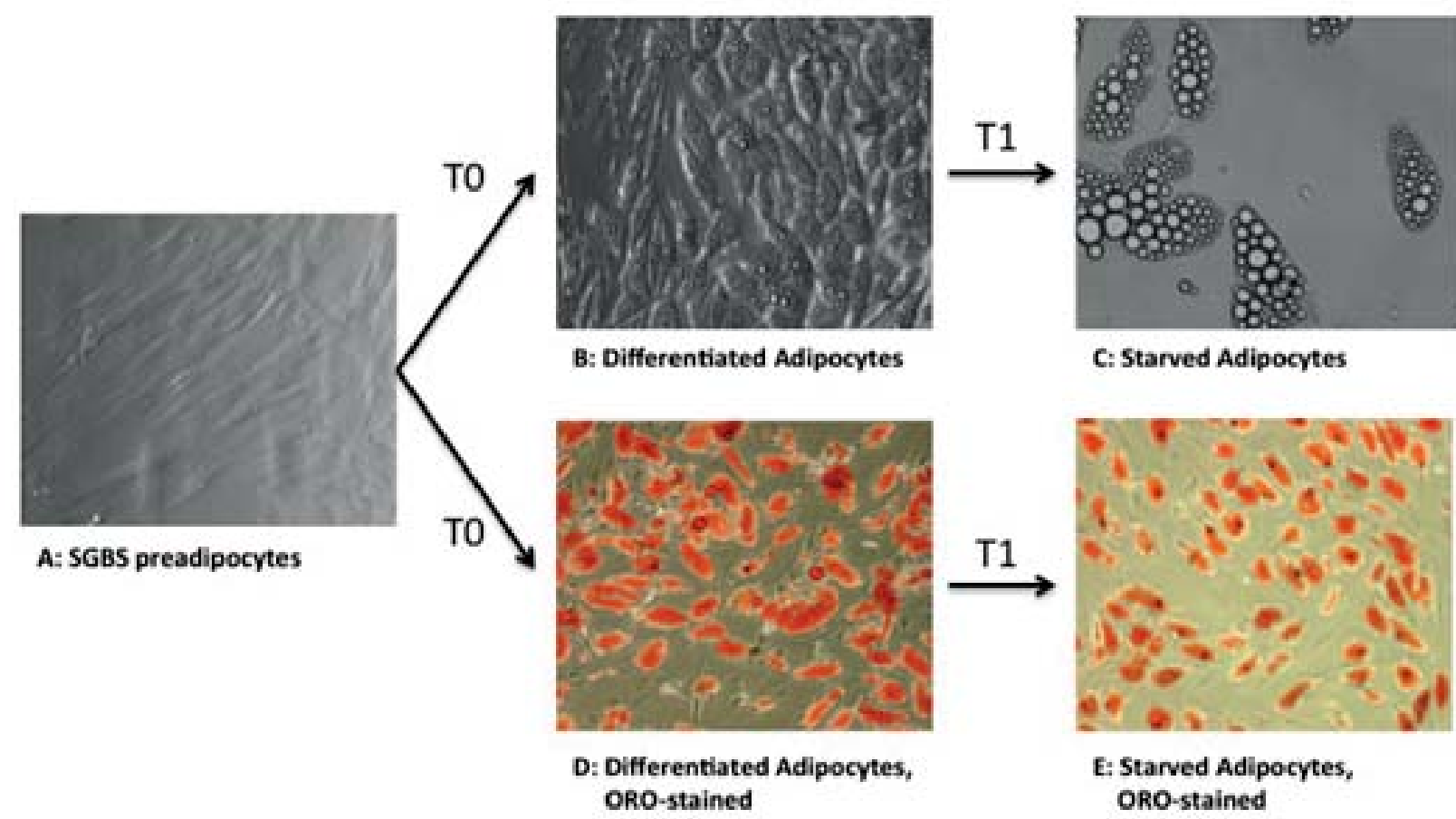

Figure 1. Representative picutres of SGBS cells. SGBS preadipocytes (A), SGBS adipocytes (B), starved SGBS adipopcytes (C). Oil Red O (ORO) stained SGBS adipocytes (D) and ORO-stained starved SGBS adipocytes (E). T0: Differentiation stage, T1: Starvation procedure by low glucose concentrations $(0.55 \mathrm{mM})$. 


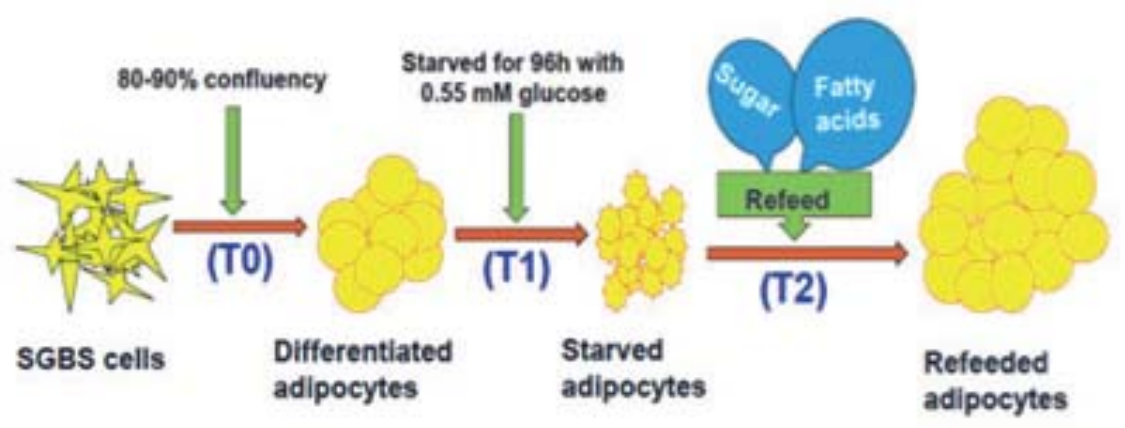

Figure 2. Experimental set-up to study the starvation and refeeding processes in SGBS adipocytes. T0: Differentiation procedure, T1: Starvation procedure with low (0.55 mM) glucose. T2: Refeeding procedure with $0.55 \mathrm{mM}-17.5 \mathrm{mM}$ glucose or 0.5 mM-5.0 mM fatty acids.

\section{References}

1. Bessesen DH. Update on obesity. J Clin Endocrinol Metab 2008; 93: 2027-2034. DOI: 10.1210/jc.2008-0520

2. Tumova J, Andel M, Trnka J. Excess of free fatty acids as a cause of metabolic dysfunction in skeletal muscle. Physiol Res 2016; 65: 193-207. PMID: 26447514

3. Milić S, Lulić D, Štimac D. Non-alcoholic fatty liver disease and obesity: biochemical, metabolic and clinical presentations. World J Gastroenterol 2014; 20: 9330-9337. DOI: 10.3748/wjg.v20.i28.9330

4. Ertunc ME, Hotamisligil GS. Lipid signaling and lipotoxicity in metaflammation: indications for metabolic disease pathogenesis and treatment. J Lipid Res 2016; 57: 2099-2114. DOI:10.1194/jlr.R066514

5. Chaldakov GN, Stankulov IS, Hristova MG, Ghenev PI. Adipobiology of disease: adipokines and adipokine-targeted pharmacology. Curr Pharm Des 2003; 9: 1023-1031. DOI: 10.2174/1381612033455152

6. Renes J, Mariman E. Application of proteomics technology in adipocyte biology. Mol Biosyst 2013; 9: 1076-1091. DOI: 10.1039/C3MB25596D
7. Varady KA, Tussing L, Bhutani S. Degree of weight loss required to improve adipokine concentrations and decrease fat cell size in severely obese women. Metabolism 2009; 58: 1096-1101. DOI: 10.1016/j.metabol.2009.04.010

8. Renes J, Rosenow A, Roumans N, Noben JP, Mariman EC. Calorie restriction-induced changes in the secretome of human adipocytes, comparison with resveratrol-induced secretome effects. Biochim Biophys Acta 2014; 1844: 15111522. DOI: 10.1016/j.bbapap.2014.04.023

9. Roumans NJ, Camps SG, Renes J, Bouwman FG, Westerterp KR, Mariman EC. Weight loss-induced stress in subcutaneous adipose tissue is related to weight regain. Br J Nutr 2016; 115: 913-920. DOI: 10.1017/S0007114515005139

10. Mariman ECM. An adipobiological model for weight regain after weight loss. Adipobiology 2011; 3: 9-15. DOI: 10.14748/ adipo.v3.265

11. Rosenow A, Noben JP, Jocken J, Kallendrusch S, FischerPosovszky P, Mariman ECM, et al. Resveratrol-induced changes of the human adipocyte secretion profile. J Proteome Res 2012; 11: 4733-4743. DOI: 10.1021/pr300539b 